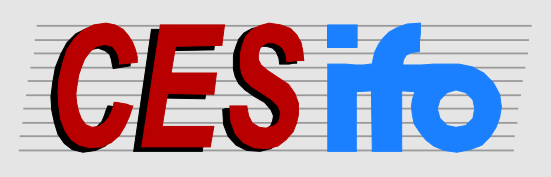

\title{
Working
}

Papers

www.cesifo.org/wp

\section{Introducing Activity-Based Payment in the Hospital Industry: Evidence from French Data}

\author{
Philippe Choné \\ Franck Evain \\ Lionel Wilner \\ Engin Yilmaz
}

CESIFO WORKING PAPER NO. 4304

CATEGORY 11: INDUSTRIAL ORGANISATION

JUNE 2013

Presented at CESifo Area Conference on Applied Microeconomics, March 2013

An electronic version of the paper may be downloaded

- from the SSRN website:

- from the RePEc website:

- from the CESifo website:

www.SSRN.com

Www.RePEc.org

www.CESifo-group.org/wp

\section{CESifo}




\title{
Introducing Activity-Based Payment in the Hospital Industry: Evidence from French Data
}

\begin{abstract}
Many countries have reformed hospital reimbursement policies to provide stronger incentives for quality and cost reduction. The purpose of this work is to understand how the effect of such reforms depends on the intensity of local competition. We build a nonprice competition model to examine the effect of a shift from global budget to patient-based payment for public hospitals in France. We predict that the number of patient admissions should increase in public hospitals by more than in private clinics and that the increase in admissions is stronger in public hospitals more exposed to competitive pressure from private clinics. Considering the reform implemented in France between 2005 and 2008, we find empirical evidence supporting these predictions.
\end{abstract}

JEL-Code: I110, I180, L330.

Keywords: health care markets, prospective payment system, local competition, not-for-profit hospitals.

\author{
Philippe Choné \\ CREST (ENSAE) \\ 92245 Malakoff cedex France \\ Philippe.Chone@ensae.fr \\ Lionel Wilner \\ CREST (INSEE) \\ 92245 Malakoff cedex France \\ wilner@ensae.fr
}

\author{
Franck Evain \\ DREES, Ministry of Health \\ Paris / France
}

\author{
Engin Yilmaz \\ DREES, Ministry of Health \\ Paris / France \\ engin.yilmaz@sante.gouv.fr
}

June 17, 2013

We thank participants at the CREST-LEI, CREST-LMI, DREES-3S and INSEE-DEE seminars as well as attendees of the "Journée Chaire Santé" workshop (Université Dauphine, Paris) and the CESIfo Applied Micro Conference (Munich), especially Robert Gary-Bobo, Nicolas Jacquemet, Florence Naegelen and Gérard de Pouvourville for their discussions. We are grateful to Vincent Dortet Bernadet, Philippe Février, Laurent Linnemer, Alain Trannoy and Michael Visser for their insightful comments. 


\section{Introduction}

Many countries have reformed their hospital reimbursement policies to provide stronger incentives for quality and managerial effort. The purpose of this article is to understand how the effect of such reforms may depend on the intensity of local competition. Our focus, therefore, is on the interaction between payment reforms and hospital competition. These results may have significant implications in terms of public policies and be taken into account by the regulator when designing the best mechanism to provide the correct incentives to health care providers.

The reform we consider is the shift from global, historical budget to patientbased payment for public and not-for-profit French hospitals between 2005 and 2008. This reform boils down to a simple change in the financial incentives of the concerned hospitals: an extra admission generated no additional revenue prereform while it did post-reform. Taking responses by other hospitals into account, we examine how the changes in equilibrium outcomes depend on local competition. We derive theoretical predictions from a nonprice competition model and test them using panel data on the number of discharges and average lengths of stay at the hospital-diagnosis related group level.

So far, payment reforms and hospital competition have mostly been studied separately. A considerable body of empirical literature, surveyed by Gaynor and Town (2012), aims at assessing welfare consequences of competition in a given policy regime. Many empirical papers try to assess the impact of competition on quality: Kessler and McClellan (2000), Propper, Burgess, and Gossage (2007), Cooper, Gibbons, Jones, and McGuire (2011) and Propper (2012) among others. These papers often consider mortality rates of the acute myocardial infarction (AMI) as the outcome. They measure competition with an Herfindahl-Hirschman Index (HHI), equal to the sum of the squares of the market shares, and instrument the latter because of potential endogeneity: more competitive markets might correspond to more dense areas where the demand is more responsive to quality. The impact of competition on quality turns out to be either positive or negative depending on the institutional environment. Using a structural model of demand for health care, Tay (2003) also focuses on AMI and concludes that patients do not substitute toward alternative hospitals, implying that geographic market concentration is an inadequate measure of hospital competitiveness.

As regards the impact of provider payment reforms, however, the empirical lit- 
erature is surprisingly thin, as pointed out by Moreno-Serra and Wagstaff (2010). Existing empirical studies on payment reforms sometimes refer to competition, but mostly in an allusive manner -or even do not tackle this issue. Ellis and McGuire (1996) mention the tightening of the distribution of lengths of stay following the introduction of prospective payments as an indicator of quality competition. Gowrisankaran, Lucarelli, Schmidt-Dengler, and Town (2011) estimate the effect of a policy reform regarding rural hospitals in the U.S., but do not address the role of competition. An exception is Herwartz and Strumann (2012). These authors find an increase of negative spatial correlation between hospital performances following the introduction of prospective reimbursement in Germany, which they interpret as a rise of local competition caused by the reform. Their dataset, however, does not contain information at the diagnosis-related group (DRG) level, and their competitive interpretation is based on rather indirect evidence.

As to theoretical studies on provider incentives, early work tended to ignore strategic interactions and equilibrium analysis. ${ }^{1}$ Several articles, Pope (1989), Ellis (1998) and Brekke, Siciliani, and Straume (2011), have investigated nonprice competition, restricting attention to symmetric equilibria. The first article assumes that hospitals choose quality expenditure and managerial slackness. The last two consider semi-altruistic providers and focus on quality choices, differing in particular as to whether or not hospitals can differentiate intensity of service according to patient severity.

In the present article, we first build a stylized model of nonprice competition, where hospitals compete in utility to attract patients. ${ }^{2}$ Unlike the theoretical articles mentioned above, however, we allow for asymmetric equilibria as well as for different hospital objectives and payment rules depending on ownership status. We examine how the payment reform affects the financial incentives of the public hospital and how this change affects the best response functions as well as the equilibria of the game. We derive a couple of reduced-form predictions as regards the relative evolution of volumes in public and private hospitals: the number of patient admissions should increase in public hospitals by more than in private clinics; the increase in admissions is stronger in public hospitals more exposed to

\footnotetext{
${ }^{1}$ For instance, Hodgkin and McGuire (1994) acknowledge that interhospital competition is missing from their model. Ma (1994) does not model competition either.

${ }^{2}$ It means that instead of competing in price or in quantity like in the usual Bertrand or Cournot frameworks, the strategic variable chosen by hospitals is the level of utility offered to patients, or attractiveness. The equilibrium concept is the same, namely the Nash equilibrium as the fixed point of best response correspondences.
} 
competitive pressure from private clinics.

Second, we check that these predictions are consistent with empirical evidence based on annual data of hospital outcomes. Our dataset includes the number of patient admissions and average lengths of stay for all DRG and all hospitals, be it subject to the payment reform or not. Controlling for (hospital, DRG) and (year, DRG) fixed effects as well as for many time-dependent hospital characteristics, we find that public and not-for-profit hospitals have increased activity by more than private clinics during the period. Our main result, however, is that these diverging trends are magnified in competitive areas. We use an indicator for local competition based on distance-weighted number of beds at neighboring hospitals.

Finally, we emphasize that the policy change applies only to public and notfor-profit hospitals, which account for about $40 \%$ of surgery activity in France. During this period, financial rules applying to for-profit hospitals (private clinics) have remained unchanged. These firms, however, are indirectly affected by the reform in equilibrium and, therefore, do not constitute a valid "control group" in the sense of public policy evaluation. As a result, we resort to a theoretical model that explains how the equilibrium should be displaced by the reform and that yields testable predictions. We do not estimate the structural model for it would require individual data; however, the predictions concern aggregated outcomes and can be confronted to market-level data.

The paper is organized as follows. Section 2 presents the main aspects of the reform at hand, introducing an activity-based payment rule and stressing the differences with the Medicare prospective payment system (PPS). Section 3 presents a nonprice competition model that accounts for asymmetric equilibria. Section 4 is devoted to the data description. Section 5 shows how market shares and average lengths of stay evolved in public hospitals and private clinics and estimates how these relative evolutions of the two groups depend on the local competitive environment. Section 6 provides an estimation of the impact of the reform in pecuniary terms. Section 7 discusses potential additional concerns and provides corresponding robustness checks. Section 8 concludes.

\section{Policy reform}

The segmentation of activity into several groups of disease, the DRG classes, dates back to the creation in 1986 of an exhaustive management information system 
that records all discharges in French hospitals (Programme de Médicalisation des Systèmes d'Information). Such a classification has been used in the US since 1982. The nature and timing of the payment reforms differed according to hospital ownership status.

\section{$2.1 \quad$ For-profit hospitals}

Before 2005, an activity-based payment applied for-profit (FP) health care providers, i.e., private clinics, and was based on DRG prices. The reimbursement rates, however, included a per diem fee: as a result, they depended on the length of stay. Moreover, these rates were negotiated annually and bilaterally between the local regulator and each clinic, and were consequently history- and geographydependent. Starting 2005, all private clinics have been reimbursed the same rate for a given DRG; moreover, after the reform, those DRG-related rates do not depend on length of stay. ${ }^{3}$ For clinics, the DRG-based reimbursement scheme has never covered physician fees (see the discussion in Section 7).

\subsection{Not-for-profit hospitals}

The reform had more dramatic consequences for public and not-for-profit (NFP) hospitals. ${ }^{4}$ Before March 2004, these hospitals were indeed funded through an annual lump-sum transfer from the government (dotation globale) which was virtually independent of the nature and evolution of their activity.

The payment reform proceeded in two stages.

An activity-based payment was gradually introduced from 2004 to 2008 in not-for-profit hospitals. In 2004, the activity-based payment applied to $10 \%$ of their resources, the remaining part being still funded by a global envelope. The activity-based part of the budget increased to $25 \%$ in 2005 , to $35 \%$ in 2006 , to $50 \%$ in 2007 and to $100 \%$ in 2008. At the end of this phase-in period, a hospital-specific "transition" coefficient is applied on DRG prices to neutralize any shocks on the public hospital's revenues. (Cour des Comptes, 2011, p. 218). So far, the reform is supposed not to have affected the financial pressure placed on public hospitals.

\footnotetext{
${ }^{3}$ Reimbursement rates, however, are adjusted downwards (resp. upwards) for exceptionally short (long) stays.

${ }^{4}$ Since public and NFP hospitals have the same payment rule, in what follows we sometimes refer to them as to not-for-profit hospitals by abuse of language.
} 
The second stage, starting at the beginning of 2009, consisted in letting the hospital-specific prices converge to a unique price schedule for all public hospitals. ${ }^{5}$ The convergence process was completed by the end of 2011. At this point, all public hospitals face the same prices and compete on a level playing field. An additional feature, however, has to be taken into account. All over the period, public hospitals keep on receiving many lump-sum transfers, designed to fund various services of general interest, research, innovation and many other projects or actions. ${ }^{6}$

The model presented in Section 3 addresses only the first part of the reform, namely the gradual shift from global budget to activity-based payment. The second part follows a different logic, related to yardstick competition (Shleifer, 1985), with hospital-specific prices changing over time. Hereafter, we concentrate on the period from 2005 to 2008 where the payment rules applying to private clinics remained constant.

\section{Theoretical framework}

We build a nonprice competition model between hospitals that are asymmetric in many dimensions, in particular their objective, size and the way they are funded. We allow for very general objective functions: as there is no consensus in the literature in that respect (particularly for not-for-profit hospitals), we allow hospitals to care about patient utility, number of admissions and profit. We model the change in financial incentives created by the shift from global budget towards activity-based payment in the case of not-for-profit hospitals only. We explain how the best response functions and the competitive equilibrium are affected.

We consider here the case of a single type of hospital viewed as a representative hospital. A private clinic and a public hospital compete in utility to attract patients. The number of patients in hospital $h, N_{h}\left(u_{h}, u_{-h}\right)$, depends positively on the utility offered by that hospital and negatively on the utility offered by its competitor. We assume that the former effect weakly dominates the latter:

$$
\frac{\partial N_{h}}{\partial u_{h}}+\frac{\partial N_{h}}{\partial u_{-h}} \geq 0
$$

with equality when demand is inelastic, i.e., when demand functions depend only

\footnotetext{
${ }^{5}$ The prices remained different from those in force for private clinics.

${ }^{6}$ Such transfers were encompassed in our model by $T^{b}$ and $T^{a}$ in (2) and (3).
} 
on the differences of offered utilities.

Prior to the reform, the revenue of the public hospital is a negotiated lump-sum transfer that does not depend on volumes:

$$
R_{h}^{b}=T_{h}^{b}
$$

The reform changed its revenue as follows:

$$
R_{h}^{a}\left(u_{h} ; u_{-h}\right)=T_{h}^{a}+p N_{h}
$$

where $p$ is the price per admission and $T_{h}^{a}$ is a lump-sum transfer. ${ }^{7}$ Hospital costs, $C_{h}\left(u_{h}, N_{h}\right)$, increase in $u_{h}$ if enhancing utility (e.g. improving perceived quality) entails a pecuniary cost. Alternatively, or cumulatively, enhancing patient utility may entail a disutility cost of "effort" that is non-pecuniary (e.g. working more, changing work habits, managerial effort). The hospital profit is the difference $\pi_{h}=R_{h}-C_{h}$.

The manager's utility is denoted by $V_{h}\left(\pi_{h}, N_{h}, u_{h}\right)$. The derivative $\partial V_{h} / \partial \pi_{h} \geq 0$ is the marginal utility of income for hospital $h$. It reflects the financial pressure on the hospital, i.e., how binding its implicit budget constraint is. The second argument reflects the manager's valuation of admitting many patients, which may come from managerial career concerns or variable non-pecuniary costs: treating more patients may generate personal spillovers for the manager, intrinsic satisfaction, or require higher effort per patient. The third argument may reflect altruism, practice style, professional ethics or a fixed non-pecuniary cost of effort.

A public hospital forms its best response by maximizing the utility $V_{h}\left(\pi_{h}, N_{h}, u_{h}\right)$ with respect to quality. Prior to the reform, the first-order condition for the public hospital choice of patient utility is

$$
-\frac{\partial V_{h}}{\partial \pi_{h}} C_{h}^{\prime}+\frac{\partial V_{h}}{\partial N_{h}} \frac{\partial N_{h}}{\partial u_{h}}+\frac{\partial V_{h}}{\partial u_{h}}=0
$$

where the notation $C_{h}^{\prime}$ refers to the total derivative of $C_{h}\left(u_{h}, N_{h}\left(u_{h} ; u_{-h}\right)\right)$ with respect to the offered utility $u_{h}$, the utility offered by the competitor $u_{-h}$ being fixed.

\footnotetext{
${ }^{7}$ After the reform, publics hospitals continued to receive lump-sum transfers for various motives (see section 4 ), which account for about $15 \%$ of the budget.
} 
After the reform, the first-order condition for public hospital becomes

$$
\underbrace{\frac{\partial V_{h}}{\partial \pi_{h}}\left(R_{h}^{\prime}-C_{h}^{\prime}\right)+\frac{\partial V_{h}}{\partial N_{h}} \frac{\partial N_{h}}{\partial u_{h}}+\frac{\partial V_{h}}{\partial u_{h}}}_{\Psi_{h}\left(\left(u_{h} ; u_{-h}\right)\right)}=0 .
$$

Let $\tau_{h}\left(u_{h} ; u_{-h}\right)$ represent the new financial incentives created by the reform:

$$
\tau_{h}\left(u_{h} ; u_{-h}\right)=\frac{\partial V_{h}}{\partial \pi_{h}} R_{h}^{\prime}=\frac{\partial V_{h}}{\partial \pi_{h}} p \frac{\partial N_{h}}{\partial u_{h}}
$$

This term is equal to the marginal revenue multiplied by the marginal utility of income. The marginal utility of income $\partial V_{h} / \partial \pi_{h}$ may vary over time. In our empirical setting, as regards public hospitals, however, the reform has been designed to be budget-neutral, so it should remain fairly constant over time. The sensitivity of the revenue with respect to the offered utility depends on the elasticity of the residual demand addressed to the hospital and hence on the local market structure around the hospital. Comparing (4) and (5), we find that the public hospital's best response functions before $\mathrm{BR}_{h}^{b}$ and after the reform $\mathrm{BR}_{h}^{a}$ satisfy

$$
\Psi_{h}\left(\mathrm{BR}_{h}^{b}\left(u_{-h}\right) ; u_{-h}\right)-\Psi_{h}\left(\mathrm{BR}_{h}^{a}\left(u_{-h}\right) ; u_{-h}\right)=\tau_{h}\left(u_{h}^{b} ; u_{-h}\right)
$$

Around the post-reform equilibrium value for $u_{-h}$, the function $\Psi_{h}$ decreases in its first argument, due to the second-order condition of the hospital problem. It follows that the payment reform causes the best response to shift upwards: $\operatorname{BR}_{h}^{a}\left(u_{-h}^{b}\right)>\operatorname{BR}_{h}^{b}\left(u_{-h}^{b}\right)$, which entails that the equilibrium has shifted from $E^{b}=$ $\left(u_{h}^{b} ; u_{-h}^{b}\right)$ before the reform to $E^{a}=\left(u_{h}^{a} ; u_{-h}^{a}\right)$ after the reform such that $u_{h}^{a}>u_{h}^{b}$ and $u_{-h}^{a}>u_{-h}^{b}$, as shown by Figure 1. By contrast, the best response of the private clinic remains unchanged over the period of study. The clinic may, however, respond to the rise in public hospital utility.

After showing that there is a change in the best response for the public hospital, while there is no such change in the private sector, we now seek to characterize the best response of the private clinic. We argue that under reasonable assumptions on the objective function and demand, the private clinic responds to the above shift by increasing the offered utility by less than the public hospital does. Before and after the reform, the revenue of private clinics is given by a formula similar to (3) and its best response function is given by a formula similar to (5). To study the qualitative properties of the best response, we simplify notations, replacing $u_{h}$, 


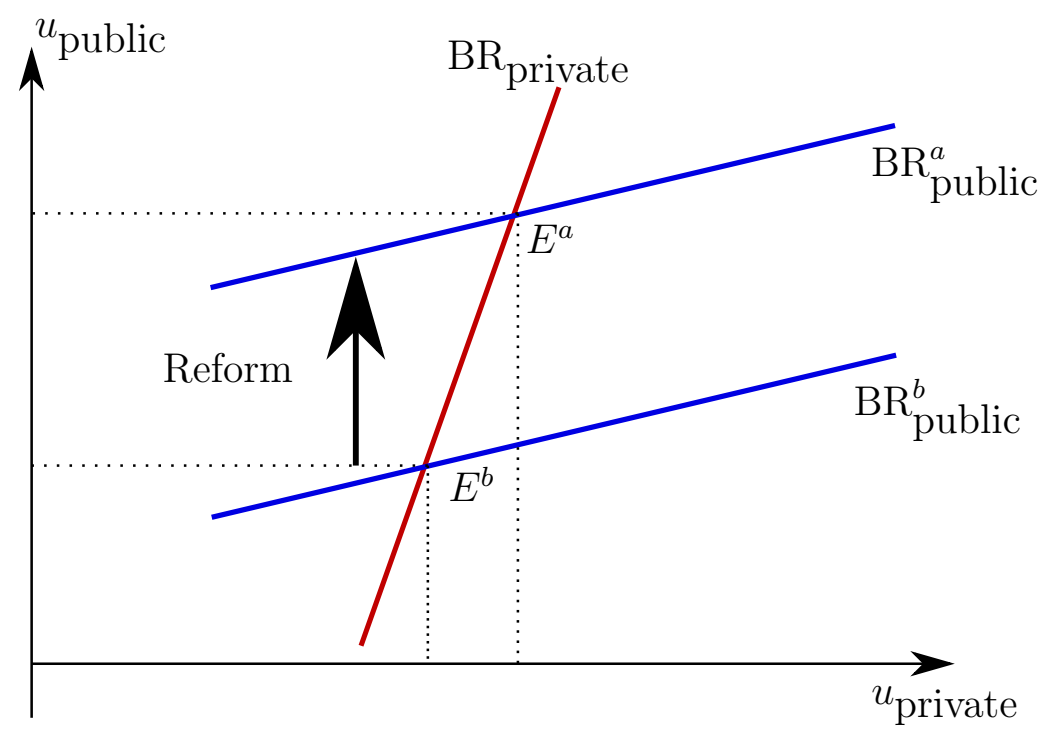

Figure 1: Pre- and post-reform equilibria

$u_{-h}, V_{h}\left(\pi_{h}, N_{h}, u_{h}\right)$ with respectively $u, u^{\prime}$ and $v(N, u)$. Indeed, the profit is an affine function of the number of admissions $N$ that depends on $u$ (and $u^{\prime}$ ) only.

Assumption 1 (Concavity). $v$ is concave in $N$ and $u$.

The private clinic's best response is then given by

$$
v_{N}(N, u) N_{u}\left(u ; u^{\prime}\right)+v_{u}(N, u)=0,
$$

together with the second-order condition

$$
\underbrace{v_{N N} N_{u}^{2}+v_{N} N_{u u}+v_{N u} N_{u}}_{A}+\underbrace{v_{N u} N_{u}+v_{u u}}_{B} \leq 0 .
$$

Differentiating (7) with respect to $u^{\prime}$ yields

$$
0=\underbrace{v_{N N} N_{u} N_{u^{\prime}}+v_{N} N_{u u^{\prime}}+v_{N u} N_{u^{\prime}}}_{C} .
$$

By the implicit function theorem, the slope of the clinic's best response is given by

$$
\mathrm{BR}^{\prime}=\frac{\partial u}{\partial u^{\prime}}=-\frac{C}{A+B} .
$$


Assumption 2 (Single-crossing). The utility of an extra admission decreases with utility: $v_{N u} \leq 0$.

Assumption 2 holds for instance when the clinic is profit-maximizing, i.e., when $v(N, u)=p N-C(N, u)$, and when the marginal costs $C_{N}$ increases with $u{ }^{8}$ Under Assumption 2, $\mathrm{BR}^{\prime}$ is smaller than one as soon as $N_{u u}+N_{u u^{\prime}}$ is not too large, so that $A+C<0$. If we further assume that demand is inelastic or linear, then we get $B R^{\prime}<1$. Indeed, when the demand is inelastic, $N_{u}+N_{u^{\prime}}=0$, which yields $C=-A$ and $\mathrm{BR}^{\prime}=A /(A+B)=1-B /(A+B)<1$. When the demand is linear, $A+C=\left[v_{N N} N_{u}+v_{N u}\right]\left[N_{u}+N_{u^{\prime}}\right]+v_{N}\left[N_{u u}+N_{u u^{\prime}}\right]=\left[v_{N N} N_{u}+v_{N u}\right]\left[N_{u}+N_{u^{\prime}}\right]<0$ which, together with $B<0$, yields $\mathrm{BR}^{\prime}<1$.

Utilities offered to patients are strategic complements when the best response is upward sloping $\left(\mathrm{BR}^{\prime}>0\right)$, which is the case if and only if $C>0$. As $N_{u^{\prime}}, v_{N u}$ and $v_{N N}$ are all negative, $C>0$ holds as soon as the term $v_{N} N_{u u^{\prime}}$ is negligible in (8), in particular when demand is linear. Strategic complementarity, therefore, is a plausible configuration, as illustrated by Gravelle, Santos, and Siciliani (2013) in the context of quality competition. ${ }^{9}$

The above analysis suggests that under reasonable assumptions the payment reform may have the impact shown on Figure 1, where the slope of the private clinic's best response is positive and smaller than one, which leads us to formulate the following predictions:

Prediction 1. During the 2005-2008 period, patient utility increases in public hospitals by more than in private clinics.

In the current paper, we do not use patient level data and hence cannot test

\footnotetext{
${ }^{8}$ It also holds when enhancing patient utility entails (fixed or per patient) non-pecuniary costs or gains that are separable from financial incentives, i.e., $v(N, u)=v_{1}(N)+v_{2}(N u)+v_{3}(u)$, where the functions $v_{1}, v_{2}$ and $v_{3}$ are concave. The non-pecuniary costs or gains may come respectively from effort disutility and altruism. They are represented by the terms $v_{2}$ and $v_{3}$ depending on whether they are per patient or fixed.

${ }^{9}$ Gravelle, Santos, and Siciliani (2013), who observe sixteen indicators of quality (readmission, mortality rates, redo rates) in a sample of English hospitals, find either complementarity (for seven indicators) or no significant link. However, their approach relies on cross-sectional evidence and their results do not come from any policy change.
} 
directly such a prediction. ${ }^{10}$ We must restrict attention to predictions on aggregated data. Prediction 1 implies that private clinics lose market shares relative to public hospitals following the payment reform. Given our framework where providers compete in utility, it leads to the following conjecture:

Prediction 2. On average, volumes increase in public hospitals by more than in private clinics.

We also derive predictions regarding the relative evolution of volumes in different public hospitals. Public hospitals that are isolated have no incentives to raise patient utility. Public hospitals that are exposed solely to competition by other public hospitals increase utility, but may not gain much market share because utility increases cancel out. This suggests our last prediction:

Hypothesis 1. Public hospitals exposed to competitive pressure from private clinics increase activity by more than public hospitals unexposed to such pressure.

\section{Data}

\subsection{A comprehensive database}

The empirical analysis relies on two comprehensive administrative sources: the Programme de Médicalisation des Systèmes d'Information and the Statistique Annuelle des Établissements de santé. The latter is a mandatory - and thus exhaustive - survey of all NFP and FP hospitals in France, containing information about equipment, staff and capacity. The former source provides information on activity (volumes, lengths of stay) for every hospital and clinic at the DRG level.

Moreover, the DRG classification (v10c) remains constant over the period 2005 - 2008; as a result, our estimation procedure is not polluted by the changes in the classification which occurred in 2005 and 2009. The payment reform might give public hospitals an incentive to inflate activity through coding optimization. We show in Section 7 that our results are robust when allowing for such a behavior.

We also collected demographic variables at the French département level, ${ }^{11}$ in

\footnotetext{
${ }^{10}$ This is the purpose of an on-going work in which we use market shares in local markets to express the relative utility gain in public hospitals in terms of travel cost economies for patients. Our ultimate goal is to estimate the slope of the private clinics' best responses and to link changes in public hospitals to the financial incentives created by the reform.

${ }^{11}$ Equivalent to a county.
} 
particular population stratified by age and gender, as well as the average income. These data are matched to hospitals according to their département.

Finally, to compute measures of local competition, we resort to the Odomatrix software developed by INRA that gives distance or travel time between zipcodes. ${ }^{12}$

\subsection{Selection of the sample}

Although the activity-based payment applies to the three types of hospital care (surgery, medical or non-surgery, and obstetrics), we concentrate on surgery only for the following reasons. First, as far as surgery is concerned, the market structure is constant over the period of study. We observe no entry, exit or merger as we do, for instance, in obstetrics. Second, to avoid our estimations from being polluted by phenomena related to supplied-induced demand, we focus on surgery, because it is less plausible in this area than for non surgery hospital care.

Table 1: Difference in differences

\begin{tabular}{|c|c|c|c|c|}
\hline & & 2005 & 2008 & diff \\
\hline & & I & II & II-I \\
\hline \multirow{3}{*}{$\begin{array}{l}\text { Number } \\
\text { of stays }\end{array}$} & $\mathrm{FP}$ & $\begin{array}{c}33.52 \\
(0.36)\end{array}$ & $\begin{array}{c}33.43 \\
(0.40)\end{array}$ & $\begin{array}{c}-0.08 \\
(0.17)\end{array}$ \\
\hline & NFP & $\begin{array}{c}24.27 \\
(0.21)\end{array}$ & $\begin{array}{c}26.35 \\
(0.24)\end{array}$ & $\begin{array}{l}2.08 \\
(0.10)\end{array}$ \\
\hline & NFP - FP & $\begin{array}{c}-9.24 \\
(0.42)\end{array}$ & $\begin{array}{c}-7.08 \\
(0.47)\end{array}$ & $\begin{array}{l}2.16 \\
(0.20)\end{array}$ \\
\hline \multirow{3}{*}{$\begin{array}{l}\text { Average } \\
\text { length } \\
\text { of stay }\end{array}$} & $\mathrm{FP}$ & $\begin{array}{c}2.75 \\
(0.004)\end{array}$ & $\begin{array}{l}2.51 \\
(0.004)\end{array}$ & $\begin{array}{c}-0.24 \\
(0.001)\end{array}$ \\
\hline & $\mathrm{NFP}$ & $\begin{array}{c}5.47 \\
(0.006)\end{array}$ & $\begin{array}{c}5.04 \\
(0.006)\end{array}$ & $\frac{-0.43}{(0.003)}$ \\
\hline & NFP - FP & $\begin{array}{l}2.72 \\
(0.006)\end{array}$ & $\begin{array}{c}2.53 \\
(0.006)\end{array}$ & $\frac{-0.19}{(0.003)}$ \\
\hline
\end{tabular}

Note. Number of stays: per hospital, DRG, year.

Average length of stay: in days.

FP: for-profit hospitals, NFP: not-for-profit hospitals.

Our working sample is a balanced panel of 730,440 observations, corresponding to 182, 610 hospital-DRG pairs observed from 2005 to 2008 and including 145, 158 zeroes (about 19.9\% of observations). To be precise, we aggregate all surgical DRGs of different severities (see Section 7 for the DRG creep issue). We are left with 1, 198 health care providers in Metropolitan France at the exclusion of Corsica:

\footnotetext{
${ }^{12} \mathrm{~A}$ zipcode is much smaller than a département and is often made up of several cities.
} 
619 of them are public or not-for-profit hospitals while 579 are for-profit private clinics. We observe 280 surgical DRGs, including 62 in ambulatory care. Every year, we consider about 5.4 million surgery stays in one of 19 clinical departments (ophthalmology, cardiology, etc.).

Summary statistics provided in Table 1 show an increase in volumes of 2.16 stays per hospital, per DRG and per year - about 8.9\% - and a reduction of 0.19 day - about $3.5 \%$ - for average lengths of stay at public hospitals relative to private clinics between 2005 and 2008. At the aggregate level, Figure 2a shows that the number of admissions in NFP hospitals increased by more over the period than in the private sector. This supplementary increase amounted to 180,000 stays.

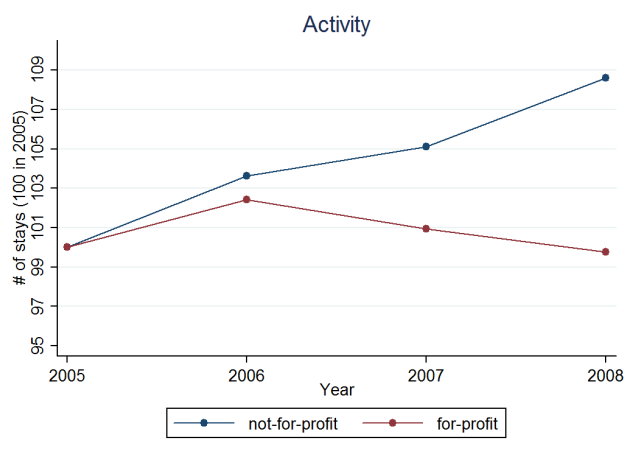

(a) Activity

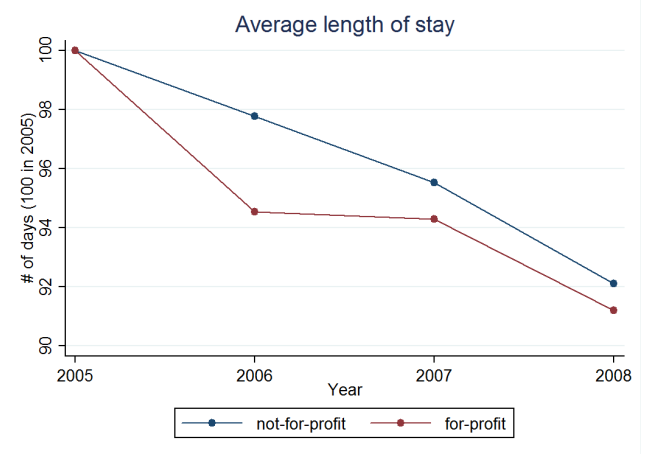

(b) Average length of stay

Figure 2: Evolution of aggregated outcomes, 2005-2008

\section{Empirical results}

Turning to our empirical specification, we seek to compare first the evolution of NFP and FP hospitals over the period 2005 - 2008 as conjectured by Prediction 2.

To this aim, we run the following regression:

$$
y_{h g t}=\beta_{t} \mathrm{NFP}_{h}+X_{h t}^{\prime} \gamma+\delta_{g t}+\xi_{h g}+\epsilon_{h g t},
$$

where $h$ indexes hospitals, $g$ DRGs and $t$ years. This OLS regression has two factors, namely hospital-DRG fixed-effects $\xi_{h g}$ and DRG-year fixed-effects $\delta_{g t}$. The former capture the average activity at the hospital-DRG level and thus account for any specialization of hospitals in some clinical departments. The latter control for possible changes in the national activity at the DRG level over the period (epidemic 
diseases, ageing of the population, technological change, specific trends for some illnesses, etc.). $X_{h t}$ are hospital-year controls that include staff covariates (number of surgeons, physicians, nurses and administrative staff); equipment covariates (computed tomography, magnetic resonance imaging, positron tomography, doppler sonography); capacity covariates (number of beds); socio-demographic covariates (average income, population stratified by age and gender). $\mathrm{NFP}_{h}$ is a dummy that is equal to 1 for not-for-profit hospitals. As a result, $\beta_{t}$ measures the evolution of NFP relative to FP hospitals in terms of outcomes $y_{\text {hgt }}$ between 2005 and 2006, 2007, 2008, once we have imposed the normalization $\beta_{2005}=0$.

Alternatively, as regards the number of admissions $n_{h g t}$, it makes sense to estimate a count model, namely a Poisson regression, to get directly the average percentage effect measured now by $\tilde{\beta}_{t}$ :

$$
n_{h g t} \sim \mathcal{P}\left(\tilde{\delta}_{g t} \tilde{\xi}_{h} e^{\tilde{\beta}_{t} \mathrm{NFP}_{h}+X_{h t}^{\prime} \tilde{\gamma}}\right)
$$

This nonlinear specification can be seen as a robustness check with respect to the functional form of the model. However, this assumption has a cost since we cannot control for as many fixed-effects as in the linear model: for computational reasons, we cannot include fixed-effects $\tilde{\xi}_{h g}$ in this nonlinear model. ${ }^{13}$ The Poisson model can be estimated by maximum likelihood, which provides a consistent estimator even in the presence of fixed effects (see Lancaster, 2000, for the treatment of incidental parameters in the FE Poisson model).

Table 2 reports results that are coherent with the descriptive evidence of Table 1: the number of stays increased by more in NFP than in FP hospitals (Column I) and the average length of stay decreased more in NFP than in FP hospitals (Column III). Moreover, these effects have been gradual over time between 2005 and 2008 : $+1 \%$ in $2006,+4.6 \%$ in 2007 and $+10.3 \%$ in 2008 . Finally, the magnitude of these effects is even amplified when controlling for fixed-effects and other covariates since the point estimate $\hat{\beta}_{2008}$ is 2.490 for activity. We reach similar conclusions with the Poisson model (Column II) since the average estimated effect is about $+9.3 \%$ and exhibits a similar temporal gradient like in the linear model. It is yet only -0.132 for the average length of stay, which amounts to about $-2.4 \%$.

\footnotetext{
${ }^{13}$ Indeed, there are $182,610 \xi_{h g}$ and $1,468 \delta_{g t}$ in Equation 9.
} 
Table 2: Estimation (without competition indicator)

\begin{tabular}{lccc}
\hline \hline & Activity & Activity & ALOS \\
\hline & OLS & Poisson & OLS \\
\hline Public $\times 2006$ & I & II & III \\
Public $\times 2007$ & $0.241^{*}$ & $0.016^{* * *}$ & 0.056 \\
Public $\times 2008$ & $(0.147)$ & $(0.001)$ & $(0.039)$ \\
& $1.119^{* * *}$ & $0.045^{* * *}$ & -0.025 \\
& $2.490^{* * *}$ & $(0.001)$ & $(0.040)$ \\
Hospital-DRG effects & $(0.151)$ & $(0.001)$ & $-0.132^{* * * *}$ \\
Hospital effects & Yes & No & Yes \\
Year-DRG effects & No & Yes & No \\
Time-varying hospital controls & Yes & Yes & Yes \\
Number of observations $N$ & 730,440 & 730,440 & 585,282 \\
$R^{2}$ & 0.96 &. & 0.78 \\
$\log L / N$ &. & -16.2 &. \\
\hline
\end{tabular}

Note. Activity: number of admissions. ALOS: average length of stay.

Sample of 1198 non-local hospitals with surgery care always present from 2005 to 2008. Metropolitan France at the exclusion of Corsica.

Hospital-year controls include equipment covariates (computed tomography, MRI, positron tomography, doppler sonography), staff covariates (physicians, surgeons, nurses, administrative staff), capacity and socio-demographic covariates (income, population).

Next, we turn to the effect of local competition (Prediction 1). We want to test whether the above evolutions are magnified when local competition is fiercer. To that purpose, we propose to measure the intensity of competition thanks to an index of local competition. A crucial issue is that this indicator must be taken as exogenous as possible, that is to say, as much orthogonal to changes in activity. Several indicators might have been considered: HHI for instance could have provided a measure of local competition. Other indicators based on activity, either at the DRG code level or at any aggregate level (like surgical "products", see infra, or at the hospital level) may be criticized for being endogenous. We choose an indicator based on capacity, namely the number of FP surgery beds. For each public hospital in the sample, we consider the number of surgery beds in private 
clinics in 2005 weighted by time/distance to that hospital $d(., h)$ :

$$
\operatorname{comp}_{h}=\sum_{i \neq h} e^{-r d(i, h)} \operatorname{beds}_{i, 2005}
$$

These quantities are computed in 2005 to avoid endogeneity issues as much as possible, i.e., to avoid any correlation between these quantities and unobserved determinants of activity from 2006 to 2008, since our estimations rely on the comparison of years 2006 to 2008 with the base year 2005. The parameter $r$ is a further degree of freedom. However, to the best of our knowledge, the choice of an adequate criterion for $r$ is not the object of any consensus in the literature. We choose to pick up some value that makes sense: $r=0.05$ meaning that a public hospital at 20 minutes time gets a weight equal to $e^{-1} \approx 0.36$, and then to provide robustness checks with respect to the choice of this particular value. Figure 3 reports the fraction of public hospitals belonging to group 3 or 4 in every département: as expected, competition is fiercer in most urban areas.

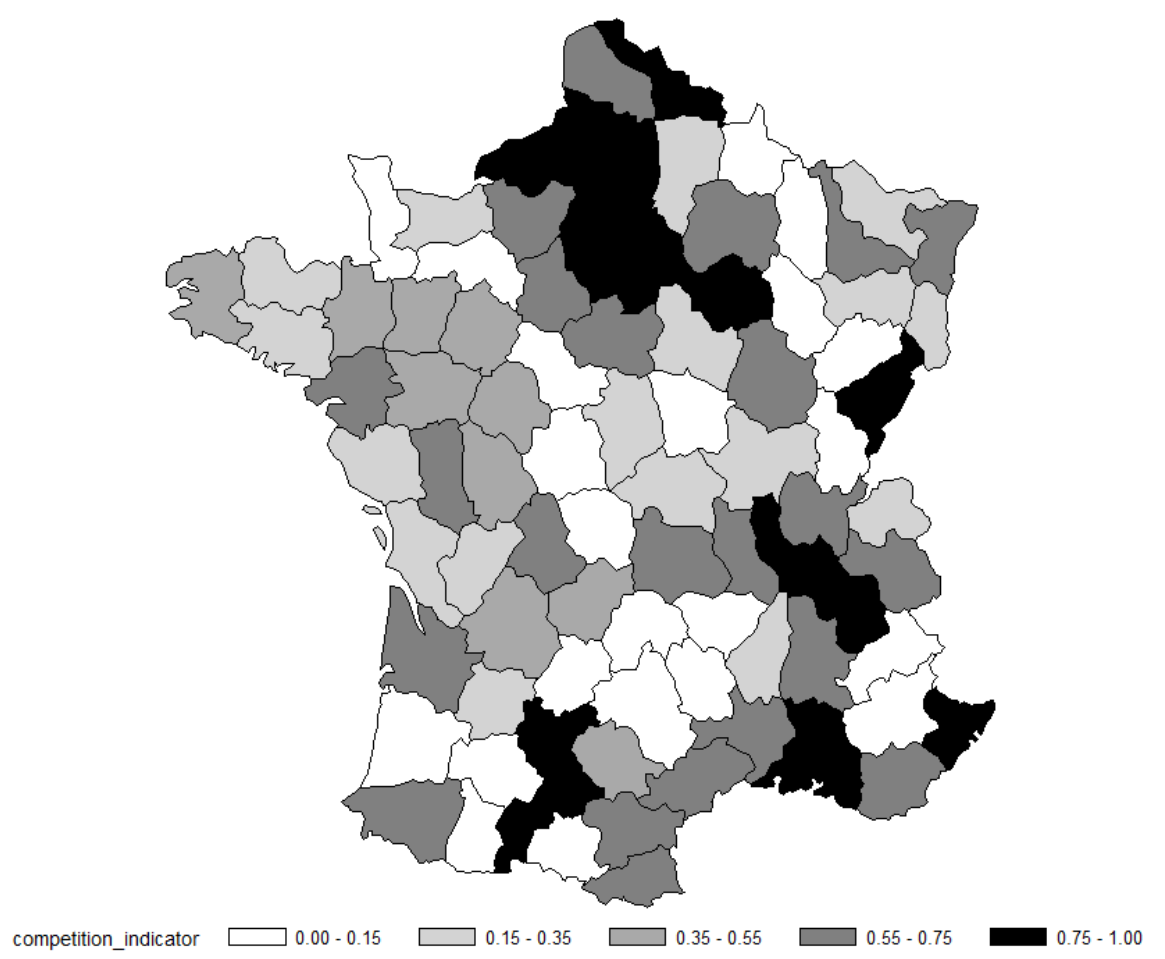

Figure 3: Départementale fraction of NFP hospitals most exposed to FP competition 
Another approach would have consisted in considering the number of beds within a given radius from the current hospital; this approach does not only involve a degree of freedom (the radius) but it also presents a discontinuity -contrary to this smooth index.

After computing the previous indicator $\operatorname{comp}_{h}$, we divide our sample of public and not-for-profit hospitals into four groups according to the quartiles of the distribution of this index. Public hospitals in group 1 (resp. group 4) are the least (most) exposed to competition from private clinics. Finally, we run the following OLS regression:

$$
y_{h g t}=\sum_{k=1}^{4} \beta_{t}^{k} \text { group } \mathrm{k}_{h(g)}+X_{h t}^{\prime} \gamma+\delta_{g t}+\xi_{h g}+\epsilon_{h g t},
$$

or estimate the Poisson model in the case of activity only:

$$
n_{h g t} \sim \mathcal{P}\left(\tilde{\delta}_{g t} \tilde{\xi}_{h} e^{\sum_{k=1}^{4} \tilde{\beta}_{t}^{k} \operatorname{group} \mathrm{k}_{h(g)}+X_{h t}^{\prime} \tilde{\gamma}}\right)
$$

The coefficients $\beta_{t}^{k}$ measure for each group $k \in \llbracket 1 ; 4 \rrbracket$ the evolution of the outcome for this group relative to FP hospitals. As a caveat, there is here an underlying assumption of homogeneity in FP hospitals' response to the reform. According to Prediction 1, the effect should increase with the degree of exposure to competition from private clinics, i.e., we expect $\beta_{t}^{k}$ to increase with $k$.

Table 3 reports the results for the number of admissions and shows that NFP hospitals in group 4 have increased volumes over the period by much more than NFP hospitals in group 1. More precisely, the effect is higher for NFP hospitals in a competitive environment than for isolated NFP hospitals. Furthermore, it is monotone in the degree of competition: $\forall t$ one has $\beta_{t}^{1}<\beta_{t}^{2}<\beta_{t}^{3}<\beta_{t}^{4}$. The gradient is pronounced, from $+3.8 \%$ for group 1 to $+10.3 \%$ for group 4 . Our estimates imply that the average public hospital in group 1 (about 1710 surgical stays every year) raises its activity by 65 stays per year, while the average public hospital in group 4 raises the number of its admissions by 556 (10.3\% of its 5397 annual stays). As noted previously, there is also a temporal gradient: for any $k$, one has $\beta_{2006}^{k}<\beta_{2007}^{k}<\beta_{2008}^{k}$, which is consistent with the progressive adoption of the patient-based payment system and with previous results from Table 2. Moreover, half of the increase occurs between 2007 and 2008, which corresponds to the gradual implementation of the reform. Overall, these estimates are consistent 
Table 3: Number of admissions $(r=0.05)$

\begin{tabular}{lcc}
\hline \hline & OLS & Poisson \\
\hline & I & II \\
\hline Public $\times$ Group $1 \times 2006$ & -0.311 & 0.003 \\
& $(0.246)$ & $(0.003)$ \\
Public $\times$ Group $1 \times 2007$ & 0.069 & 0.003 \\
& $(0.250)$ & $(0.003)$ \\
Public $\times$ Group $1 \times 2008$ & $0.975^{* * *}$ & $0.038^{* * *}$ \\
& $(0.253)$ & $(0.003)$ \\
\hline Public $\times$ Group $2 \times 2006$ & -0.052 & $0.016^{* * *}$ \\
& $(0.237)$ & $(0.003)$ \\
Public $\times$ Group $2 \times 2007$ & $0.928^{* * *}$ & $0.056^{* * *}$ \\
Public $\times$ Group $2 \times 2008$ & $(0.239)$ & $(0.003)$ \\
& $1.854^{* * *}$ & $0.097^{* * *}$ \\
& $(0.241)$ & $(0.003)$ \\
\hline Public $\times$ Group $3 \times 2006$ & $0.417^{*}$ & $0.015^{* * *}$ \\
Public $\times$ Group $3 \times 2007$ & $(0.219)$ & $(0.002)$ \\
Public $\times$ Group $3 \times 2008$ & $1.407^{* * *}$ & $0.051^{* * *}$ \\
& $(0.222)$ & $(0.002)$ \\
Public $\times$ Group $4 \times 2006$ & $2.996^{* * *}$ & $0.104^{* * *}$ \\
& $(0.226)$ & $(0.002)$ \\
Public $\times$ Group $4 \times 2007$ & $0.761^{* * *}$ & $0.022^{* * *}$ \\
Public $\times$ Group $4 \times 2008$ & $(0.237)$ & $(0.002)$ \\
& $1.861^{* * *}$ & $0.051^{* * *}$ \\
& $(0.244)$ & $(0.002)$ \\
Hospital-DRG effects & $3.824^{* * *}$ & $0.103^{* * *}$ \\
Hospital effects & $(0.248)$ & $(0.002)$ \\
Year-DRG effects & Yes & No \\
Time-varying hospital controls & No & Yes \\
Number of observations $N$ & Yes & Yes \\
$R^{2}$ & 730,440 & 730,440 \\
log $L / N$ & 0.96 & $\cdot$ \\
&. & -16.2 \\
\hline
\end{tabular}

Sample of 1198 non-local hospitals with surgery care always present from 2005 to 2008 .

Metropolitan France at the exclusion of Corsica.

Hospital-year controls include equipment covariates (computed tomography, MRI, positron tomography, doppler sonography), staff covariates (physicians, surgeons, nurses, administrative staff), capacity and socio-demographic covariates (income, population).

Group 1: least exposed to FP-competition.

Group 2: second least exposed to FP-competition.

Group 3: second most exposed to FP-competition.

Group 4: most exposed to FP-competition. 
Table 4: Average length of stay $(r=0.05)$

\begin{tabular}{lc}
\hline \hline Public $\times$ Group $1 \times 2006$ & 0.085 \\
Public $\times$ Group $1 \times 2007$ & $(0.068)$ \\
Public $\times$ Group $1 \times 2008$ & $(0.070)$ \\
& -0.052 \\
\hline Public $\times$ Group $2 \times 2006$ & $0.071)$ \\
Public $\times$ Group $2 \times 2007$ & $(0.064)$ \\
Public $\times$ Group $2 \times 2008$ & 0.006 \\
& $(0.065)$ \\
& -0.038 \\
Public $\times$ Group $3 \times 2006$ & $(0.066)$ \\
Public $\times$ Group $3 \times 2007$ & 0.019 \\
& $(0.057)$ \\
Public $\times$ Group $3 \times 2008$ & -0.045 \\
& $(0.058)$ \\
Public $\times$ Group $4 \times 2006$ & $-0.158^{* * *}$ \\
Public $\times$ Group $4 \times 2007$ & $-0.059)$ \\
Public $\times$ Group $4 \times 2008$ & $(0.062)$ \\
& -0.059 \\
Hospital-DRG effects & $(0.064)$ \\
DRG-year effects & $-0.241^{* * *}$ \\
Time-varying hospital controls & Yes \\
Number of observations & Yes \\
$R^{2}$ & 585,282 \\
\hline Same legend as Table 3. & 0.78 \\
\hline
\end{tabular}

with Prediction 1 on NFP hospitals: the more exposed to competition from private clinics, the higher the increase in volumes relative to private clinics. Even isolated hospitals from group 1 increase volumes relative to FP hospitals: since the FP sector has decreased over the period, this relative increase is indeed mechanical.

Results for average length of stay are reported in Table 4. Overall, the estimates show that the average length of stay (ALOS hereafter) has been more reduced in NFP than in FP hospitals. The magnitude of this reduction varies with the degree of competition: hospitals in a competitive environment have reduced their average ALOS by almost -0.24 day, namely $-4.4 \%$, while isolated hospitals have hardly decreased at all. This reduction is found to be monotone with competition. Again, we observe that the effect has been progressive over time since there is a temporal gradient as well. 
One can wonder whether these findings are driven by the fact that group 4 contains mostly hospitals in the Paris region. We thus perform the analysis by removing this region from the sample (in particular when defining our competition measures). Estimates are given in Appendix A, Table 5, and lead to the same result: the gradient with competition is even more pronounced. Also, we provide robustness checks with respect to the value of the parameter $r$ used in competition indexes (Tables 6 and 7). Overall, the gradient with competition remains significant.

\section{Budget impact of the reform}

The reform entailed some pecuniary cost for the National Health Insurance. It has been designed to be budget-neutral should patients behaviors remain unchanged. Yet, as explained previously, the equilibrium has been displaced in the sense of more attractiveness of not-for-profit hospitals resulting in an increase of demand. More patients were admitted in public hospitals where reimbursements are higher on average than in private clinics. Indeed, the private tariff does not include the part of physician fees that is reimbursed by the national health insurance. In surgery, the average tariff is $€ 2760$ in NFP hospitals while it is only $€ 1200$ in FP hospitals, given the repartition of surgical stays into the different DRGs. From aggregated data on those fees gathered by the National Health Insurance, we estimate that these fees amount to $€ 580$ on average, which therefore yields a difference of $€ 980$ between public and private hospitals. Since the impact of the reform has been assumed to be homogeneous across DRGs, we estimate that the supplementary cost for the national health insurance amounted to $€ 54$ million in 2006 and to $€ 200$ million in 2007. Finally, it amounted to $€ 313$ million in 2008, i.e., about $2.1 \%$ of the annual budget devoted to surgery. ${ }^{14}$

\section{Discussion and robustness checks}

First, it must be recognized that the reform gives public hospital a novel incentive to optimize their coding strategy and even to game the payment rules ("DRG creep"). The most common behavior documented by practitioners consists of

\footnotetext{
${ }^{14}$ Doctors in private clinics may charge extra fees not covered by the public insurance (see below). As regards these fees, the reform has translated into an economy for patients and supplementary insurers.
} 
assigning cases to high-severity DRGs, e.g. DRGs associated with co-morbidities and complications. In practice, a pair of DRG codes may share the same diagnosis but one DRG code corresponds to low-severity diseases while the other DRG code is related to high-severity cases. Indeed, the number of more severe cases has increased over the period and one might fear that this would drive our results. Dafny (2005) documented this "upcoding" phenomenon in the US case. This is the reason why the previous analysis was done at the diagnosis level, by pooling pairs of DRG codes with different severities. Nevertheless, in Appendix B, Table 8, Column I, we present regression results obtained at the DRG code level. Not only do results remain, but they also tend to be of the same magnitude, which comforts our findings. We also use a higher degree of aggregation in Table 8, Column II (groups of DRG codes related to "products" such as cataract surgery or orthopedic surgery). Considering this higher level of aggregation, we ignore any effect linked to the possibly increasing share of discharges with high severity in public hospitals. As regards the number of admissions, the results vary very little with the degree of DRG aggregation. The results about average length of stays are far less robust.

Second, the payment reform might give public hospitals an incentive to artificially increase the number of stays by discharging and readmitting patients. Our findings on average length of stays might even suggest that the activity-based reform induces public hospital to discharge patients prematurely, hence deteriorating quality of care. The health economics literature, however, mostly considers average length of stay as an indicator for efficiency and does not suggest that low ALOS should be associated with poor quality. Most studies indeed find no or negative correlation between ALOS and quality, e.g. Thomas, Guire, and Horvat (1997).

Based on patient data, we have computed the fraction of discharges followed by a readmission within 30 days. As shown in Appendix C, we indeed find that readmissions increase more rapidly ceteris paribus in public hospitals, from $7.5 \%$ to $8.0 \%$ over the period, than in private clinics, from $6.3 \%$ to $6.9 \%$ over the period. The magnitude of the coefficient, however, is very weak and the effect is nonmonotonic in time (very weak and insignificant in 2007). More importantly, we find that the readmission rate increases more rapidly in public hospital less exposed to competition by private hospitals (see Table 11). This result does not support the hypothesis that the effect of competition found in this paper would be driven by an increase in readmissions (and possibly a quality deterioration). Although we 
do not offer any formal explanation for the stronger reduction in average length of stay at public hospitals, we tend to relate this fact to an increase in efficiency. ${ }^{15}$

Third, as already mentioned, the activity-based payment in force in the private sector does not cover physician fees which are charged to consumers. Fees are partially covered by the basic mandatory insurance. Most patients have a supplementary insurance that covers all or part of the copayment. Unfortunately we had access only to very aggregate data regarding physician fees. Specifically, we observe the total amount of fees charged by surgeons and anesthesiologists at the département level and the share of that amount in excess of the regulated price, i.e., in excess of the price covered by the basic insurance. The results ${ }^{16}$ show no correlation in the data between public hospital volumes and physician fees in the private sector. Volumes in public hospitals do not increase more rapidly in départements with the highest rise in surgeon fees. Controlling for physician fees in the volume equations leads to an extremely weak coefficient and affects none of the coefficients of interest.

Finally, we mention a limitation of this work. Both the theoretical model and the empirical analysis presented here ignore the multi-product dimension of hospital care. The payment reform might cause public hospitals to specialize in certain cases, products or DRGs. We believe, however, that specialization is a second-order issue given the short period of time under study (2005-2008). In our opinion, the first-order effect comes from the financial incentives created by the new payment rule: an extra patient admission generates extra resources after the reform while it did not before. This signal is simple enough and is easily understood by all hospital managers. We therefore have estimated an average effect over all DRGs that reflects the overall impact of this force.

\section{Conclusion}

To sum up, we provided empirical evidence that local competition affects the way the equilibrium shifted. First, activity in NFP hospitals raised all the more after the reform than hospitals are in a competitive environment. This fact is consistent

\footnotetext{
${ }^{15}$ The reduction in ALOS could also follow from capacity constraints. If public hospitals were capacity constrained, the increase in admissions would mechanically imply a decrease in ALOS. The occupation rates for surgery, defined as (number of stays $\times$ ALOS)/(number of surgery beds $\times 365$ ), shown on Appendix D, Figure 4, however, do not suggest strong capacity constraints.

${ }^{16}$ These results are available upon request.
} 
with Prediction 1 claiming that the increase in the NFP market share after the reform should be more pronounced as competition is fiercer. Second, the average length of stay has been more reduced in NFP hospitals relative to FP hospitals and again, this effect is stronger when competitive pressure is more intense.

In this paper, we have used data at the hospital-DRG level to test reducedform predictions regarding the relative evolutions of volumes in public hospitals and private clinics following the adoption of a patient-based payment system in the public sector. Testing more detailed predictions about hospital nonprice competition requires more disaggregated data. In an on-going work, we use market shares in local markets to express the relative utility gain at public hospitals in terms of travel cost economies for patients. Ultimately, we plan to estimate the slope of the private clinics' best responses and to link more precisely the behavior of the public hospitals to the financial incentives created by the reform. 


\section{References}

Brekke, K. R., L. Siciliani, and O. R. Straume (2011): "Hospital Competition and Quality with Regulated Prices," Scandinavian Journal of Economics, 113(2), 444-469.

Cooper, Z., S. Gibbons, S. Jones, And A. McGuire (2011): "Does Hospital Competition Save Lives? Evidence From The English NHS Patient Choice Reforms," The Economic Journal, 121(554), 228-260.

Cour Des Comptes (2011): "La mise en oeuvre de la T2A : bilan à mi-parcours," in La Sécurité Sociale.

Dafny, L. S. (2005): "How Do Hospitals Respond to Price Changes?," American Economic Review, 95(5), 1525-1547.

ELLIS, R. P. (1998): "Creaming, skimping and dumping: provider competition on the intensive and extensive margins," Journal of Health Economics, 17, 537-555.

Ellis, R. P., AND T. G. MCGuire (1996): "Hospital response to prospective payment: Moral hazard, selection, and practice-style effects," Journal of Health Economics, 15, 257-277.

Gaynor, M., and R. J. Town (2012): "Competition in Health Care Markets," in Handbook of Health Economics, vol. 2, pp. 499-637. Elsevier B.V.

Gowrisankaran, G., C. Lucarelli, P. Schmidt-Dengler, and R. Town (2011): "The Impact of the Medicare Rural Hospital Flexibility Program on Patient Choice," International Journal of Industrial Organization, 29(3), 342344.

Gravelle, H., R. Santos, and L. Siciliani (2013): "Does a hospital's quality depend on the quality of other hospitals? A spatial econometrics approach to investigating hospital quality competition," Discussion paper.

Herwartz, H., and C. Strumann (2012): "On the effect of prospective payment on local hospital competition in Germany," Health Care Management Science, $15(1), 48-62$.

Hodgkin, D., And T. G. MCGuire (1994): "Payment levels and hospital response to prospective payment," Journal of Health Economics, 13, 1-29. 
Kessler, D. P., And M. B. MCClellan (2000): "Is hospital competition socially wasteful?," The Quarterly Journal of Economics, 115(2), 577-615.

LANCASTER, T. (2000): "The incidental parameter problem since 1948," Journal of Econometrics, 95(2), 391-413.

MA, C.-T. A. (1994): "Health care payment systems: Cost and quality incentives," Journal of Economics \& Management Strategy, 3(1), 93-112.

Moreno-Serra, R., And A. Wagstaff (2010): "System-wide impacts of hospital payment reforms: Evidence from Central and Eastern Europe and Central Asia," Journal of Health Economics, 29, 585-602.

Pope, G. C. (1989): "Hospital nonprice competition and Medicare reimbursement policy," Journal of Health Economics, 8, 147-172.

Propper, C. (2012): "Competition, incentives and the English NHS," Health Economics, 21(1), 33-40.

Propper, C., S. Burgess, and D. Gossage (2007): "Competition and quality: Evidence from the NHS internal market 1991-9," The Economic Journal, 118(525), 138-170.

Shleifer, A. (1985): "A theory of yardstick competition," The RAND Journal of Economics, 16(3), 319-327.

TAY, A. (2003): "Assessing Competition in Hospital Care Markets: The Importance of Accounting for Quality Differentiation," The RAND Journal of Economics, 34(4), 786-814.

Thomas, J., K. Guire, and G. Horvat (1997): "Is patient length of stay related to quality of care?," Hospital $\&$ health services administration, 42(4), 489. 


\section{Appendix}

\section{A Robustness checks}

Table 5: Without Île-de-France $(r=0.05)$

\begin{tabular}{lccc}
\hline \hline & \multicolumn{2}{c}{ Activity } & ALOS \\
\hline & OLS & Poisson & OLS \\
\hline Public $\times$ Group $1 \times 2006$ & -0.224 & $0.009^{* * *}$ & 0.105 \\
& $(0.273)$ & $(0.003)$ & $(0.074)$ \\
Public $\times$ Group $1 \times 2007$ & 0.204 & $0.009^{* * *}$ & -0.039 \\
& $(0.277)$ & $(0.003)$ & $(0.076)$ \\
Public $\times$ Group $1 \times 2008$ & $1.276^{* * *}$ & $0.051^{* * *}$ & -0.075 \\
& $(0.279)$ & $(0.003)$ & $(0.077)$ \\
\hline Public $\times$ Group $2 \times 2006$ & 0.086 & $0.024^{* * *}$ & 0.041 \\
& $(0.261)$ & $(0.003)$ & $(0.069)$ \\
Public $\times$ Group $2 \times 2007$ & $0.997^{* * *}$ & $0.058^{* * *}$ & -0.070 \\
& $(0.263)$ & $(0.003)$ & $(0.070)$ \\
Public $\times$ Group $2 \times 2008$ & $1.940^{* * *}$ & $0.094^{* * *}$ & $-0.169^{* * *}$ \\
& $(0.265)$ & $(0.003)$ & $(0.071)$ \\
\hline Public $\times$ Group $3 \times 2006$ & 0.010 & $0.012^{* * *}$ & $0.035^{* *}$ \\
& $(0.251)$ & $(0.002)$ & $(0.065)$ \\
Public $\times$ Group $3 \times 2007$ & $0.970^{* * *}$ & $0.045^{* * *}$ & -0.079 \\
& $(0.252)$ & $(0.002)$ & $(0.065)$ \\
Public $\times$ Group $3 \times 2008$ & $2.422^{* * *}$ & $0.098^{* * *}$ & -0.088 \\
& $(0.254)$ & $(0.002)$ & $(0.066)$ \\
\hline Public $\times$ Group $4 \times 2006$ & $1.211^{* * *}$ & $0.026^{* * *}$ & 0.018 \\
Public $\times$ Group $4 \times 2007$ & $(0.240)$ & $(0.002)$ & $(0.060)$ \\
& $2.187^{* * *}$ & $0.054^{* * *}$ & $-0.107^{*}$ \\
Public $\times$ Group $4 \times 2008$ & $(0.244)$ & $(0.002)$ & $(0.062)$ \\
& $4.467^{* * *}$ & $0.114^{* * *}$ & $-0.277^{* * *}$ \\
& $(0.250)$ & $(0.002)$ & $(0.064)$ \\
\hline Hospital-DRG effects & Yes & Yes & Yes \\
Year-DRG effects & Yes & Yes & Yes \\
Hospital-year controls & Yes & Yes & Yes \\
Number of observations $N$ & 596,288 & 596,288 & 477,446 \\
$R^{2}$ & 0.96 &. & 0.78 \\
log $L / N$ &. & -15.5 &. \\
\hline & & & \\
\hline & & & \\
& & &
\end{tabular}

Same legend as Table 3. 
Table 6: Robustness checks for activity - Role of the parameter $r$

\begin{tabular}{|c|c|c|c|}
\hline & $r=0.025$ & $r=0.075$ & $r=0.1$ \\
\hline Public $\times$ Group $1 \times 2006$ & $\begin{array}{c}-0.160 \\
(0.240)\end{array}$ & $\begin{array}{c}-0.343 \\
(0.249)\end{array}$ & $\begin{array}{c}-0.302 \\
(0.247)\end{array}$ \\
\hline Public $\times$ Group $1 \times 2007$ & $\begin{array}{l}0.298 \\
(0.245)\end{array}$ & $\begin{array}{l}0.174 \\
(0.252)\end{array}$ & $\begin{array}{l}0.246 \\
(0.250)\end{array}$ \\
\hline Public $\times$ Group $1 \times 2008$ & $\underset{(0.247)}{1.311^{* * *}}$ & $\begin{array}{c}1.063^{* * *} \\
(0.255)\end{array}$ & $\begin{array}{c}1.095^{* * *} \\
(0.252)\end{array}$ \\
\hline Public $\times$ Group $2 \times 2006$ & $\begin{array}{l}0.138 \\
(0.228)\end{array}$ & $\begin{array}{l}0.015 \\
(0.247)\end{array}$ & $\begin{array}{c}-0.005 \\
(0.257)\end{array}$ \\
\hline Public $\times$ Group $2 \times 2007$ & $\begin{array}{c}1.197^{* * *} \\
(0.231)\end{array}$ & $\begin{array}{c}0.709^{* * *} \\
(0.249)\end{array}$ & $\begin{array}{c}0.807^{* * *} \\
(0.258)\end{array}$ \\
\hline Public $\times$ Group $2 \times 2008$ & $\begin{array}{c}2.353^{* * *} \\
(0.233)\end{array}$ & $\begin{array}{c}1.679^{* * *} \\
(0.251)\end{array}$ & $\begin{array}{c}1.924^{* * *} \\
(0.259)\end{array}$ \\
\hline Public $\times$ Group $3 \times 2006$ & $\begin{array}{c}0.637^{* * *} \\
(0.229)\end{array}$ & $\begin{array}{l}0.195 \\
(0.215)\end{array}$ & $\begin{array}{l}0.037 \\
(0.216)\end{array}$ \\
\hline Public $\times$ Group $3 \times 2007$ & $\begin{array}{c}1.586^{* * *} \\
(0.232)\end{array}$ & $\begin{array}{c}1.135^{* * *} \\
(0.217)\end{array}$ & $\begin{array}{c}0.928^{* * *} \\
(0.218)\end{array}$ \\
\hline Public $\times$ Group $3 \times 2008$ & $\begin{array}{c}3.561^{* * *} \\
(0.235)\end{array}$ & $\begin{array}{c}2.593^{* * *} \\
(0.219)\end{array}$ & $\begin{array}{c}2.306^{* * *} \\
(0.220)\end{array}$ \\
\hline Public $\times$ Group $4 \times 2006$ & $\begin{array}{l}0.306 \\
(0.238)\end{array}$ & $\begin{array}{c}0.910^{* * *} \\
(0.231)\end{array}$ & $\begin{array}{c}1.017^{* * *} \\
(0.224)\end{array}$ \\
\hline Public $\times$ Group $4 \times 2007$ & $\begin{array}{c}1.314^{* * *} \\
(0.244)\end{array}$ & $\underset{(0.238)}{2.181^{* * *}}$ & $\begin{array}{c}2.220^{* * *} \\
(0.230)\end{array}$ \\
\hline Public $\times$ Group $4 \times 2008$ & $\begin{array}{c}2.623^{* * *} \\
(0.247)\end{array}$ & $\begin{array}{c}4.183^{* * *} \\
(0.241)\end{array}$ & $\begin{array}{c}4.188^{* * *} \\
(0.234) \\
\end{array}$ \\
\hline Hospital-DRG effects & Yes & Yes & Yes \\
\hline Year-DRG effects & Yes & Yes & Yes \\
\hline Hospital-year controls & Yes & Yes & Yes \\
\hline Number of observations & 730,440 & 730,440 & 730,440 \\
\hline$R^{2}$ & 0.96 & 0.96 & 0.96 \\
\hline
\end{tabular}


Table 7: Robustness checks for average length of stay - Role of the parameter $r$

\begin{tabular}{cccc}
\hline \hline & $r=0.025$ & $r=0.075$ & $r=0.1$ \\
\hline Public $\times$ Group $1 \times 2006$ & $0.146^{* *}$ & 0.096 & 0.084 \\
& $(0.065)$ & $(0.069)$ & $(0.068)$ \\
Public $\times$ Group $1 \times 2007$ & 0.026 & -0.029 & -0.061 \\
& $(0.067)$ & $(0.071)$ & $(0.070)$ \\
Public $\times$ Group $1 \times 2008$ & -0.028 & -0.092 & -0.092 \\
& $(0.068)$ & $(0.072)$ & $(0.071)$ \\
\hline Public $\times$ Group $2 \times 2006$ & 0.075 & 0.047 & 0.025 \\
& $(0.061)$ & $(0.067)$ & $(0.069)$ \\
Public $\times$ Group $2 \times 2007$ & 0.040 & 0.013 & -0.030 \\
& $(0.062)$ & $(0.068)$ & $(0.070)$ \\
Public $\times$ Group $2 \times 2008$ & -0.074 & -0.072 & -0.099 \\
& $(0.063)$ & $(0.069)$ & $(0.071)$ \\
\hline Public $\times$ Group $3 \times 2006$ & 0.024 & 0.070 & 0.081 \\
& $(0.059)$ & $(0.056)$ & $(0.057)$ \\
Public $\times$ Group $3 \times 2007$ & $-0.182^{* * *}$ & -0.030 & -0.003 \\
& $(0.061)$ & $(0.057)$ & $(0.057)$ \\
Public $\times$ Group $3 \times 2008$ & $-0.216^{* * *}$ & $-0.110^{*}$ & $-0.102^{*}$ \\
& $(0.062)$ & $(0.057)$ & $(0.058)$ \\
\hline Public $\times$ Group $4 \times 2006$ & -0.009 & 0.020 & 0.031 \\
& $(0.062)$ & $(0.060)$ & $(0.058)$ \\
Public $\times$ Group $4 \times 2007$ & 0.032 & -0.041 & -0.021 \\
Public $\times$ Group $4 \times 2008$ & $(0.064)$ & $(0.062)$ & $(0.060)$ \\
& $-0.198^{* * *}$ & $-0.225^{* * *}$ & $-0.208^{* * *}$ \\
& $(0.065)$ & $(0.063)$ & $(0.061)$ \\
\hline Hospital-DRG effects & Yes & Yes & Yes \\
Year-DRG effects & Yes & Yes & Yes \\
Hospital-year controls & Yes & Yes & Yes \\
Number of observations & 585,282 & 585,282 & 585,282 \\
$R^{2}$ & 0.78 & 0.78 & 0.78 \\
\hline Same legend as Table 3. & & & \\
& & &
\end{tabular}




\section{B Aggregation level}

We address here the concern that NFP hospitals might have optimized their coding strategy and that this would drive our results.

Table 8: Various aggregation levels: DRG, Product (without competition indicator).

\begin{tabular}{|c|c|c|}
\hline & \multicolumn{2}{|c|}{ Activity (Poisson) } \\
\hline Aggregation level & DRG & Product \\
\hline & $\mathrm{I}$ & II \\
\hline Public $\times 2006$ & $\begin{array}{c}0.017^{* * *} \\
(0.001)\end{array}$ & $\begin{array}{c}0.025^{* * *} \\
(0.001)\end{array}$ \\
\hline Public $\times 2007$ & $\begin{array}{c}0.045^{* * *} \\
(0.001)\end{array}$ & $\begin{array}{c}0.036^{* * *} \\
(0.001)\end{array}$ \\
\hline Public $\times 2008$ & $\begin{array}{c}0.094^{* * *} \\
(0.001)\end{array}$ & $\begin{array}{c}0.078^{* * *} \\
(0.002)\end{array}$ \\
\hline Hospital effects & Yes & Yes \\
\hline Year-DRG effects & Yes & Yes \\
\hline Time-varying hospital controls & Yes & Yes \\
\hline Number of observations & 951,324 & 201,856 \\
\hline $\log L / N$ & -12.9 & -31.5 \\
\hline
\end{tabular}

Same legend as Table 2.

Until now, we have considered the "root" level of aggregation that groups up to two DRGs of different severities. First, we consider an aggregation level specific to the true DRG (Column I of Tables 8 and 9). Second, we consider a higher aggregation level, namely product classification, further reducing the number of observations (see Tables 8, Column II, and 9, Column II). Results are reassuringly stable; the effects are similar in magnitude. 
Table 9: Various aggregation levels: DRG, Product (with competition indicator).

\begin{tabular}{|c|c|c|}
\hline \multirow{3}{*}{ Aggregation level } & \multicolumn{2}{|c|}{ Activity (Poisson) } \\
\hline & DRG & Product \\
\hline & $\mathrm{I}$ & II \\
\hline Public $\times$ Group $1 \times 2006$ & $\begin{array}{l}0.003 \\
(0.003)\end{array}$ & $\begin{array}{c}0.013^{* * *} \\
(0.003)\end{array}$ \\
\hline Public $\times$ Group $1 \times 2007$ & $\begin{array}{l}0.003 \\
(0.003)\end{array}$ & $\begin{array}{l}0.001 \\
(0.003)\end{array}$ \\
\hline Public $\times$ Group $1 \times 2008$ & $\begin{array}{c}0.038^{* * *} \\
(0.003)\end{array}$ & $\begin{array}{c}0.028^{* * *} \\
(0.003)\end{array}$ \\
\hline Public $\times$ Group $2 \times 2006$ & $\begin{array}{c}0.017^{* * *} \\
(0.003)\end{array}$ & $\begin{array}{c}0.024^{* * *} \\
(0.003)\end{array}$ \\
\hline Public $\times$ Group $2 \times 2007$ & $\begin{array}{c}0.056^{* * *} \\
(0.003)\end{array}$ & $\underset{(0.003)}{0.047^{* * *}}$ \\
\hline Public $\times$ Group $2 \times 2008$ & $\begin{array}{c}0.098^{* * *} \\
(0.003)\end{array}$ & $\begin{array}{c}0.084^{* * *} \\
(0.003)\end{array}$ \\
\hline Public $\times$ Group $3 \times 2006$ & $\begin{array}{c}0.015^{* * *} \\
(0.002)\end{array}$ & $\begin{array}{c}0.024^{* *} \\
(0.002)\end{array}$ \\
\hline Public $\times$ Group $3 \times 2007$ & $\begin{array}{c}0.051^{* * * *} \\
(0.002)\end{array}$ & $\begin{array}{c}0.043^{* * * *} \\
(0.002)\end{array}$ \\
\hline Public $\times$ Group $3 \times 2008$ & $\begin{array}{c}0.104^{* * *} \\
(0.002) \\
\end{array}$ & $\begin{array}{c}0.088^{* * *} \\
(0.002) \\
\end{array}$ \\
\hline Public $\times$ Gro & $\begin{array}{c}0.022^{* * *} \\
(0.002)\end{array}$ & $\begin{array}{c}0.030^{* * *} \\
(0.002)\end{array}$ \\
\hline Public $\times$ Group & $\begin{array}{c}0.051^{* * * *} \\
(0.002)\end{array}$ & $\begin{array}{c}0.038^{* * *} \\
(0.002)\end{array}$ \\
\hline Public $\times$ Group $4 \times 2008$ & $\begin{array}{c}0.103^{* * *} \\
(0.002) \\
\end{array}$ & $\begin{array}{c}0.083^{* * *} \\
(0.002) \\
\end{array}$ \\
\hline Hospital effects & Yes & Yes \\
\hline Year-DRG effects & Yes & Yes \\
\hline Time-varying hospital controls & Yes & Yes \\
\hline Number of observations & 951,324 & 201,856 \\
\hline $\log L / N$ & -12.9 & -31.5 \\
\hline
\end{tabular}

Same legend as Table 3. 


\section{Readmission rates}

A readmission is defined as an admission within 30 days of a discharge. Readmissions rates have been treated the same way as average length of stay. We observe on Tables 10 and 11 a higher increase of the readmission rate in the public sector. However, the increase is stronger for public hospitals that are less exposed to competition from private clinics.

Table 10: 30-day readmission rates (without competition indicator).

\begin{tabular}{lc}
\hline \hline Public $\times 2006$ & $0.003^{* *}$ \\
& $(0.001)$ \\
Public $\times 2007$ & 0.001 \\
$(0.001)$ \\
Public $\times 2008$ & $0.003^{* *}$ \\
& $(0.001)$ \\
\hline Hospital-DRG effects & Yes \\
Year-DRG effects & Yes \\
Time-varying hospital controls & Yes \\
Number of observations & 730,440 \\
$R^{2}$ & 0.96 \\
\hline \multicolumn{2}{c}{ Same legend as Table 2. }
\end{tabular}


Table 11: 30-day readmission rates (with competition indicator).

\begin{tabular}{lc}
\hline \hline Public $\times$ Group $1 \times 2006$ & $0.005^{*}$ \\
& $(0.002)$ \\
Public $\times$ Group $1 \times 2007$ & $0.006^{* *}$ \\
& $(0.003)$ \\
Public $\times$ Group $1 \times 2008$ & $0.008^{* * *}$ \\
& $(0.003)$ \\
\hline Public $\times$ Group $2 \times 2006$ & 0.003 \\
& $(0.002)$ \\
Public $\times$ Group $2 \times 2007$ & 0.002 \\
& $(0.002)$ \\
Public $\times$ Group $2 \times 2008$ & 0.003 \\
& $(0.002)$ \\
\hline Public $\times$ Group $3 \times 2006$ & 0.003 \\
& $(0.002)$ \\
Public $\times$ Group $3 \times 2007$ & 0.000 \\
Public $\times$ Group $3 \times 2008$ & $(0.002)$ \\
& 0.003 \\
Public $\times$ Group $4 \times 2006$ & $0.002)$ \\
Public $\times$ Group $4 \times 2007$ & $(0.002)$ \\
Public $\times$ Group $4 \times 2008$ & 0.000 \\
& $(0.002)$ \\
Hospital-DRG effects & 0.000 \\
Year-DRG effects & Yes \\
Time-varying hospital controls & Yes \\
Number of observations & 730,440 \\
$R^{2}$ & 0.96 \\
\hline Same legend as Table 3. &
\end{tabular}




\section{Occupation rates}

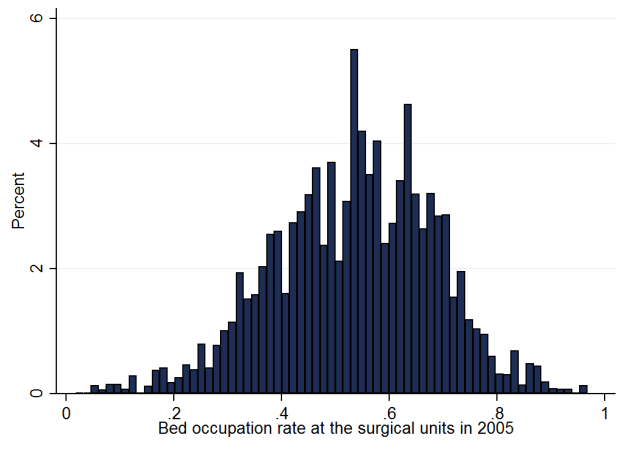

(a) 2005

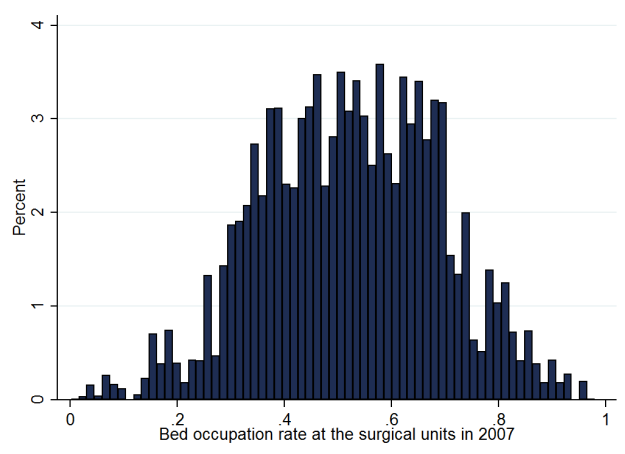

(c) 2007

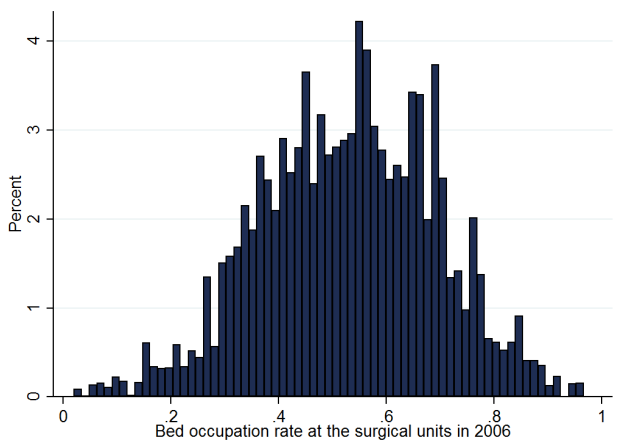

(b) 2006

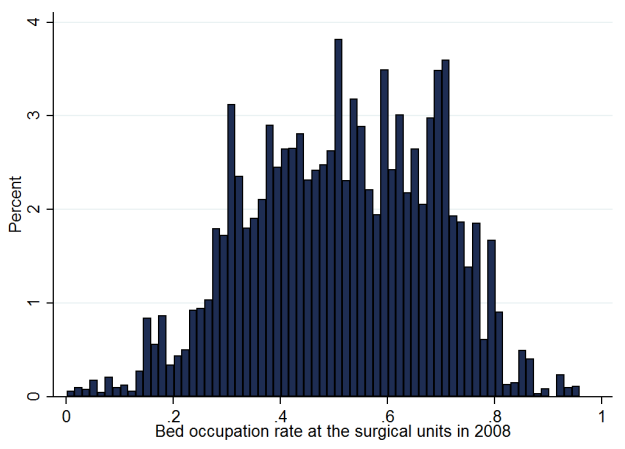

(d) 2008

Figure 4: Occupation rates (weighted by admissions) 


\section{E Physician fees}

The CNAMTS provided département level data on overcharge fees for surgeons and anesthesiologists (source: SNIR-PS). Data is based on the invoices received by the National Health Insurance.

First we check that controlling for physician fees in private clinics leads to a very weak coefficient and does not alter our results.

Second, we constructed four groups of départements based on the quartiles of the distribution of the increase of the overcharge ratio

$$
\frac{\text { total fees in excess of the regulated price }}{\text { total fees }} \text {. }
$$

On average, this ratio rose from $27.4 \%$ in 2005 to $29.9 \%$ in 2008 . We did the same exercise with the increase of the mean overcharge

total fees in excess of the regulated price. number of admissions

On average, the mean overcharge rose from $€ 135$ in 2005 to $€ 175$ in 2008.

We do not find any correlation between the increase in surgeons fees at private clinics and the increase in volumes in the public hospitals. It should be noted that the incentives of physicians and of private clinics are not perfectly aligned. Surgeons pay a rental fee to the clinics to use the facilities, e.g. operating room, but clinics are also remunerated through the DRG prices. It is therefore not in their interest that surgeons and anesthesiologists charge very high fees. The design of contracts between physicians and clinics is outside the scope of this paper. 